\title{
Edirne Selimiye Külliyesinde Bilinmeyen Bir Çeşme
}

\author{
N. Çiçek Akçıl Harmankaya* $₫$
}

Öz

Çeşme, sebil ve şadırvan gibi su yapılarını inşa edilmesi daima en önemli hayırların başında gelmiştir. Bunlar içinde çeşmeler en yaygın görülen su yapılarındandır. Bir mahallenin, bir sokağın bazen de külliyenin bir parçası olarak cami cemaatinin su ihtiyacını karşılamak üzere bir hayır eseri olarak inşa edilmişlerdir.

Mimar Sinan'ın ustalık eseri Edirne Selimiye Camii, kent merkezinde, Kavak Meydanı olarak adlandırılan bir yükseltide eski saray (Saray-ı Atik) alanında inşa edilmiştir. Sultan II. Selim tarafindan 1568-1574 yılları arasında inşa edilen yapı küçük bir külliyeyi meydana getirmektedir. Sinan'ın tezkire ve vakfiyeleri ile Dayezâde Mustafa Efendi'nin Selimiye Risale'sinde de bahsedilmeyen, mimarı ve inşa tarihi bilinmeyen Edirne Selimiye Külliyesi duvar çeşmesi çalışma konumuzu oluşturmaktadır. Bu çalışmada Edirne Selimiye Külliyesinin kuzey dış avlu duvarı üzerinde yer alan çeşmesi, mimari özellikleri bakımından ilk kez tanıtlarak, bulunduğu konum, yapı ve inşa dönemi açısından incelenmiştir. Mimar Sinan'ın su yapıları içinde az bilinen çeşmeleri açısından önemi üzerinde durularak, Edirne çeşmeleri ve çeşme mimarisi açısından bir değerlendirmesi yapılmıştır.

\section{Anahtar Kelimeler}

Osmanlı Mimarisi • Edirne • Selimiye Külliyesi • Çeşme

\section{An Unknown Fountain in the Edirne Selimiye Complex}

\begin{abstract}
Building water structures such as fountains, sebil or a sadirvan has always been an important charitable deed. These were built as works of charity to provide water for a district or street, or for mosque communities as part of a social complex.

The Edirne Selimiye Mosque, masterwork of Sinan the Architect, was built on the old palace grounds on a ridge called Kavak Meydanı. The structure, built by Sultan Selim II between 1568 and 1574, constitutes a small social complex. This paper examines the wall fountain of the Edirne Selimiye Complex, which was built by an anonymous architect at an unknown date and is not mentioned in the biographies and pious endowment charters of Sinan or in the Selimiye Booklet by Dayezâde Mustafa Efendi. The fountain on the northern outer court wall of the Edirne Selimiye Complex is introduced for the first time in this paper by its architectural characteristics and examined for its location, construction and period. The paper also discusses the importance of the fountain among the relatively unknown examples built by Sinan, and evaluates it within the context of fountains and fountain architecture in Edirne.
\end{abstract}

\section{Keywords}

Ottoman Architecture $\bullet$ Edirne $\bullet$ Selimiye Complex $\bullet$ Fountain

* Sorumlu Yazar: N. Çiçek Akçıl Harmankaya (Dr. Öğr. Üyesi), İstanbul Üniversitesi, Mimarlık Fakültesi, Mimarlık Bölümü, İstanbul, Türkiye. Eposta: nesrin.akcilharmankaya@istanbul.edu.tr ORCID: 0000-00023077-5144

Atif: AKCIL HARMANKAYA, N. Cicek, "Edirne Selimiye Külliyesinde Bilinmeyen Bir Çeşme", Art-Sanat, 12(Temmuz 2019), s. 1-18. https://doi.org/10.26650/artsanat.2019.12.0004 


\section{Extended Summary}

The Islamic religion has always placed great importance on water. Therefore, building a water structure such as a fountain, sebil or a sadirvan has always been an important charitable deed, and fountains constitute the most common group. Fountains, exclusively charity works built inside settlements as generally independent structures, can be divided into groups like sadirvan fountains, column fountains, wall fountains, freestanding fountains, pit fountains, window fountains and fork fountains. They were built for charity to provide water for a district or street, or for mosque communities as part of a social complex.

It is known that approximately 125 fountains were built in Edirne, which was the capital of the Ottoman Empire for a long period. The wall fountain of the Selimiye Complex is not among the currently nonextant or unused fountains. This paper examines the wall fountain of the Edirne Selimiye Complex, which was built by an anonymous architect at an unknown date, does not have an inscription nor is mentioned in the biographies and pious endowment charters of Sinan the Architect or in the Selimiye Booklet by Dayezâde Mustafa Efendi.

The study shows that the complex has been extensively analyzed in terms of its layout, architectural characteristics and decorations, whereas the fountain has never been studied. This paper introduces the fountain on the northern outer court wall of the complex for the first time in terms of its architectural characteristics and examines it in terms of location, construction and period. The paper also discusses the importance of the fountain among the relatively unknown ones built by Sinan, and evaluates it within the context of fountains and fountain architecture in Edirne.

The Edirne Selimiye Mosque, Sinan's masterpiece, was built on the old palace grounds (Saray-1Atik) on a ridge called Kavak Meydanı. The structure, built by Sultan Selim II in 1568-1574, constitutes a small social complex. Buildings making up the complex are located inside a large, rectangular courtyard, and the mosque consists of a darülhadis medrese (hadith school) in the southeast, a darülkurra medrese (Quran school) in the southwest, and a row of shops, a time setter house and a primary school in the west. The shops bound the complex, which is surrounded by walls on three sides around the mosque and outer courtyard.

The fountain on the northern outer courtyard wall is one-sided, approximately $140 \times 120$ centimeters in size. Shaped as a shallow niche on the wall, the fountain has a cusped quadricentric arch. The fountain, which has a 40-centimeter-wide inscription gap above the arch bears no inscriptions of repair or construction. The structure lacks an ornamental slab, and the shallow niche features a spout with a cascaded and multifoil arch. This section, currently filled with cement, is shaped like a bowl seat, and the vat stone was seemingly replaced. On both sides ring holes are visible, which 
probably had chains attached to drinking bowls. In certain examples, these are used as clips to fix the tap. A plastic pipe, presumably connecting the fountain to a water outlet, is visible between the paving stones. The simple wall fountain has no reservoir. The women's bathroom is located behind the structure. It is thought that water was supplied from the same water line, or the old Palace bathhouse, for the fountain and bathroom.

It appears that Sinan generally integrated such water structures into complexes on courtyard walls instead of freestanding fountains. Wall fountains are frequently seen in Sinan's designs before and after Selimiye, like in Istanbul Suleymaniye Mosque (1550-1557), Silivrikapı Hadım İbrahim Pasha Mosque (1551), Kadirga Sokollu Mehmet Pasha Mosque (1567-1572), Üsküdar Atik Valide Mosque (1571-1584), Yedikule Haci Evhad Mosque (1585), and Fatih Mesih Mehmed Pasha Mosque (15841586).

Analogs of the fountain designed as a shallow niche on the courtyard wall were used by Sinan on sebil fountains on both sides of the gate inside the Selimiye Mosque. Like these structures, known as vat fountains, the upper section of the fountain's vat the base of the niche - is believed to be shaped like a circular bench. Fountains of this type stand in the legs of central gate on the outer courtyard wall of the Sultanahmet Mosque, facing the courtyard. Design similarities with the Selimiye fountain manifest in the master-apprentice relationship between Sedefkâr Mehmed Agha and Sinan in an architectural expression in the Sultanahmet Complex.

Fountains generally have inscriptions above their ornaments or arches, seen as stone or marble slabs with inscriptions of the builder's name, construction date, and Quran verses and hadiths about water as a masthead.

In conclusion, the unknown and previously unstudied wall fountain shows that the Edirne Selimiye Complex had another water structure along with a sadirvan, ablution taps, sebil fountains inside both sides of the entrance, and the octagonal pool under the muezzin's platform. It is presumed that this fountain, unmentioned in the biographies and pious endowment charters of Sinan like his many other fountains, was arranged as a sebil fountain on the northern outer courtyard walls. This structure, presumably designed by Sinan, was possibly completed after the mosque along with outer courtyard walls and the spolia column. 


\section{Giriş}

İslam dini her zaman suya büyük önem vermiştir. Hz. Muhammed'in de "Sadakanın en faziletlisi su teminidir" dediği bilinmektedir ${ }^{1}$. Bu nedenle de çeşme, sebil ve şadırvan gibi su yapılarının inşa edilmesi en önemli hayırların başında gelmektedir. Bunlar içinde çeşmeler en yaygın görülen su yapılarındandır. Osmanlı döneminde yerleşim yerlerinin içinde yapılan, hepsi de birer hayrat olan ve genellikle bağımsız yapılar olarak inşa edilen çeşmeleri; şadırvan çeşmeler, sütun çeşmeler, duvar çeşmeler, meydan çeşmeler, çukur çeşmeler, pencere çeşmeler ve çatal çeşmeler gibi gruplara ayırmak mümkündür² ${ }^{2}$ Bir mahallenin, bir sokağın bazen de külliyenin bir parçası olarak cami cemaatinin su ihtiyacını karşılamak üzere bir hayır olarak inşa edilmişlerdir.

Osmanlı İmparatorluğuna uzun bir süre başkentlik yapmış olan Edirne şehrinde yaklaşık 125 çeşme inşa edildiği araştırmalarda bahsedilmektedir³. Günümüzde birçoğu yok olmuş ya da kullanılmayan bu çeşmeler arasında Selimiye Külliyesi duvar çeşmesi yer almamaktadır.

Sinan'ın tezkire ${ }^{4}$ ve vakfiyeleri ${ }^{5}$ ile Dayezâde Mustafa Efendi'nin Selimiye Risale'sinde ${ }^{6}$ de bahsedilmeyen, mimarı ve inşa tarihi bilinmeyen bu kitabesiz çeşme çalışma konumuzu oluşturmaktadır.

Yapılan araştırmada Selimiye Külliyesi plan, mimari ve süsleme özellikleri bak1mından çokça incelendiği ancak çeşmesi üzerinde hiç durulmadığ dikkati çekmektedir. Bu çalışmada söz konusu çeşme mimari özellikleri bakımından ilk kez tanıtılmış, bulunduğu konum, yapı ve inşa dönemi açısından incelenmiştir. Mimar Sinan'ın az bilinen çeşmeleri arasındaki önemi üzerinde durularak Edirne çeşmeleri ve çeşme mimarisi açısından bir değerlendirmesi yapılmıştır.

1 Semavi Eyice, "Çeşme”, Türkiye Diyanet Vakfı İslam Ansiklopedisi, C.8, İstanbul 1993, s.277-287; İbrahim Canan, "Osmanlı'da Su Kültürü ve Kaynakları", Osmanlı Su Medeniyeti Uluslararası Sempozyum Bildiriler (5-8 Mayıs 2000), İstanbul 2000, s. 231-244.

2 Çeşme mimarisine ilişkin detaylı bilgi için bkz. Semavi Eyice, "Çeşme, a.g.e, s. 277-287; Yılmaz Önge, “Anadolu Beylikler Döneminin Çeşme, Sebil ve Şadırvanları", Uluslararası Osmanlı Öncesi Türk Külttïrü Kongresi Bildirileri (4-7 Eylül 1989 Ankara,) Ankara 1997, s. 199-214; Yılmaz Önge, “XI. Yüzyıldan XIX. Yüzyıla Kadar Anadolu Su Mimarisinde Çeşme, Sebil ve Şadırvanlar”, Türk Mimarisinde Selçuklu ve Osmanlı Dönemlerinde Su Yapıları, Ankara 1997, s. 11-19.

3 Edirne çeşmeleri hakkında detaylı bilgi için bkz. Murat Karademir, Edirne Çeşmeleri, Edirne 2008; Neriman Meriç Köylüoğlu, Edirne’de Osmanlı'dan Günümüze Su Yapıları, Edirne 2001.

4 Zeki Sönmez, Mimar Sinan İle İlgili Tarihi Yazmalar-Belgeler, Mimar Sinan Üniversitesi Yayınları, İstanbul 1988; Sâî Mustafa Çelebi, Yapılar Kitabı (Tezkiretü'l-Bünyan ve Tezkiretü'l-Ebniye) Mimar Sinan'm Anıları, Çev. Hayati Develi-Samih Rifat, İstanbul 2002.

5 Rauf Tuncay, "Edirne'de Selimiye Camii”, Belgelerle Türk Tarihi Dergisi, S. 23, Ankara 1969, s. 3.

6 Z. Sönmez, a.g.e., 


\section{Edirne Selimiye Külliyesi ve Çeşmesi}

Mimar Sinan'ın ustalık eseri olarak kabul edilen ${ }^{7}$ Edirne Selimiye Camii, kent merkezinde, Kavak Meydanı olarak adlandırılan bir yükseltide eski saray (Saray-1 Atik) alanında inşa edilmiştir ${ }^{8}$. II. Selim tarafından 1568-1574 (976-982) y1lları arasında inşa edilen yapı küçük bir külliyeyi meydana getirmektedir. Külliyeyi oluşturan yapılar büyük dikdörtgen bir avlunun içinde yer almakta olup ortada cami, güney doğuda darülhadis medresesi, güneybatıda darülkurra medresesi batıda ise arasta, muvakkithane ve sıbyan mektebinden meydana gelmektedir. Arasta'nın batı yönündeki dükkânları, tonozlu üst örtüsü, dua kubbesi ve sıbyan mektebinin III. Murad döneminde Mimar Davud Ağa tarafından inşa edildiği kabul edilmektedir. Batıda arasta ile sınırlanan külliyenin, camiyi de içine alan, dış avlusu üç yönden çevre duvarları ile çevrilidir 9 . Yapının kuzeyindeki dış avlu duvarlarının üzerinde daha önce hiçbir kaynakta belirtilmeyen bir duvar çeşmesi yer almaktadır (G. 1-2).

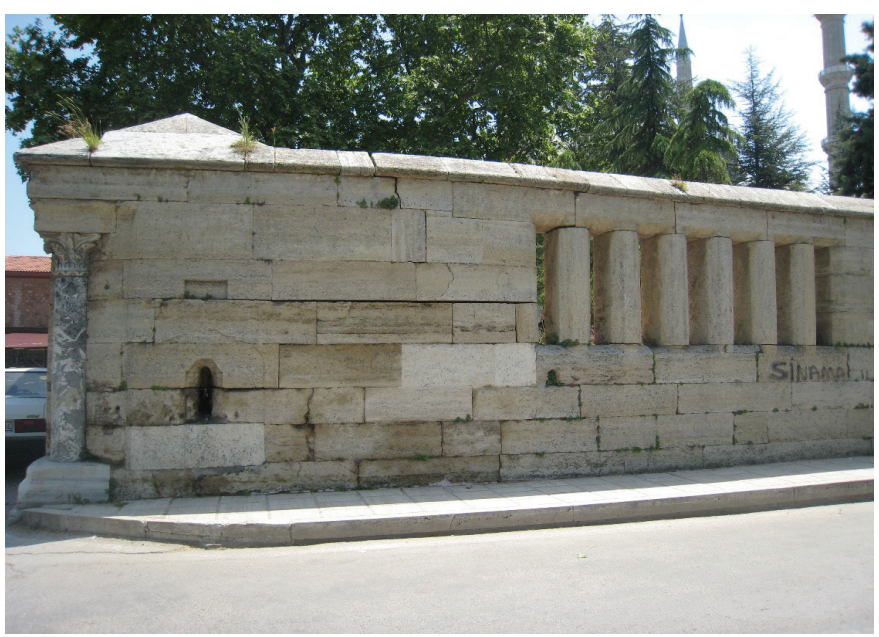

G. 1. Selimiye Külliyesi kuzey cephesi dış avlu duvarları ve çeşmesi

(N.Ç. Akçıl Harmankaya, 2018)

747 selatin cami yaptım ve 140 mescit, 30 adet Sultan hanı, 140 ayan sarayı, 120 köprü, yedi adet su kemerleri ve nice bin ileri gelenlere ve seçkinlere haneler ve saraylar yapıp handese ilminde çok sanat icra edip zamanın seçkini oldum, ama kalfalığımı İstanbul'da Şehzade Camii’nde icra ettim. Ustalığımı Süleymaniye Camii'nde tamamladım, ama bütün gücümü ve becerimi bu Selim Han Camii’nde sarf edip uzmanlığımı açık seçik ortaya koydum. Cihan mimar ve mühendisleri bütün güçlerini ve becerilerini harcasalar böyle büyük bir eser yapmaya güçleri yetmez. Ve bir padişah bu kadar çok mal harcamaya cüret edemez...” Evliya Çelebi, Günümüz Türkçesiyle Evliya Çelebi Seyahatnamesi, Haz. Seyit Ali Kahraman, Yücel Dağl1, 3. Kitap, İstanbul 2016, s. 324.

8 Caminin inşa edildiği alanda Sultan I. Bayezid tarafından Edirne'nin ilk sarayı Saray-1 Atik inşa edilmişti (...), R. Tuncay, a.g.e., s. 3.

9 Selimiye Camii ve Külliyesinin mimarisi hakkında detaylı bilgi için bkz. Aptullah Kuran, Mimar Sinan, İstanbul 1986; Z. Sönmez, a.g.e.,; Neslihan Sönmez, Zeki Sönmez, "Tarihi Belgelerin Işığında Edirne Selimiye Camii”, Uluslararası Mimar Sinan Sempozyumu Bildirileri (Ankara, 24-27 Ekim 1988), Ankara 1996, s. 73-79; Doğan Kuban, Sinan'ın Sanatı ve Selimiye, İstanbul 1997; Doğan Kuban, Osmanlı Mimarisi, İstanbul, 2007; Ernst Egli, Osmanlı Altın Çağının Mimarı Sinan, Çev. ve Der. İbrahim Ataç, İstanbul 2009; Selçuk Mülayim, Ahmet Vefa Çobanoğlu, "Selimiye Camii ve Külliyesi”, Türkiye Diyanet Vakfı İslam Ansiklopedisi, C. 36, İstanbul 2009, s.430-434. 


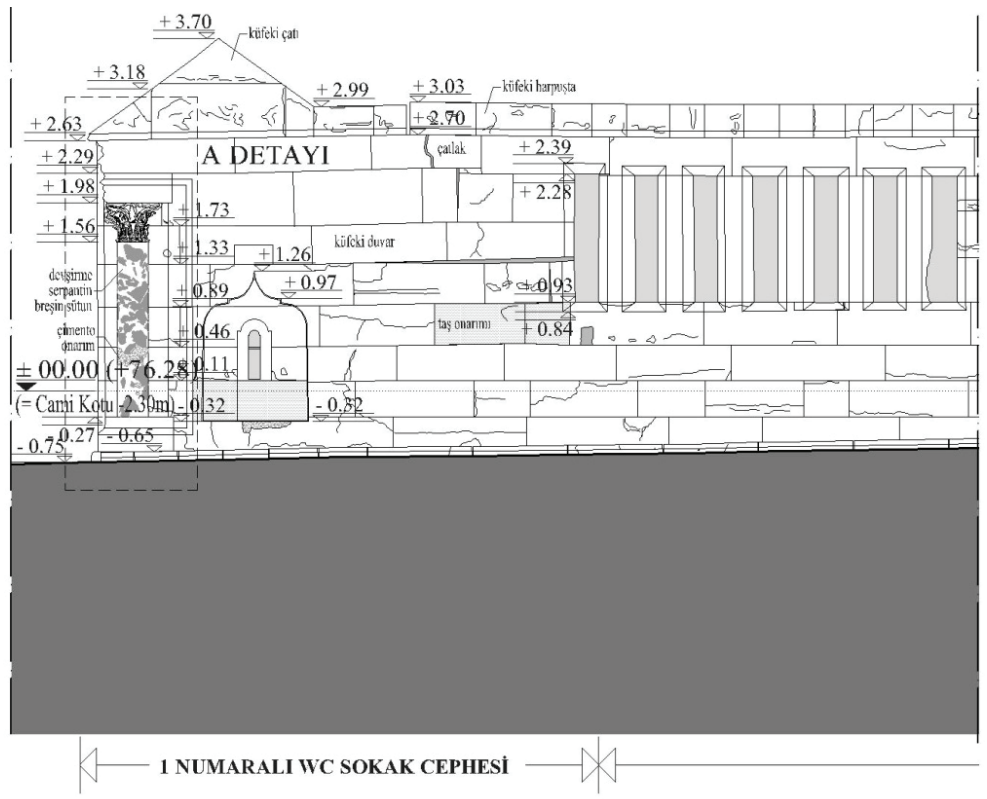

\section{ÖN GÖRÜNÜŞ ÖLÇEK: 1/50}

G. 2. Selimiye Külliyesi Kuzey Cephe Rölövesi (Acar Avunduk Mimarlık, 2017)

Yapının giriş cephesini teşkil eden kuzey çevre duvarları Mimar Sinan Caddesi üzerinde, batıda Arasta'dan başlayarak doğuda Taş Odalar Sokağı köşesinde sona ermektedir. Genellikle üç metreye ulaşan yükseklik ve $60-65 \mathrm{~cm}$. arasında değişen genişlikteki bu duvarlar büyük ölçüde kesme küfeki taşından mazgallı olarak yapılmış olup üzerleri yine kesme taştan harpuşta ile kapatılmıştır. Kuzey doğu köşesine yakın bir noktada ise mazgallı duvar dokusu sona ermekte olup bu duvar üzerinde bir cephe çeşmesi dikkati çekmektedir (G. 3). 


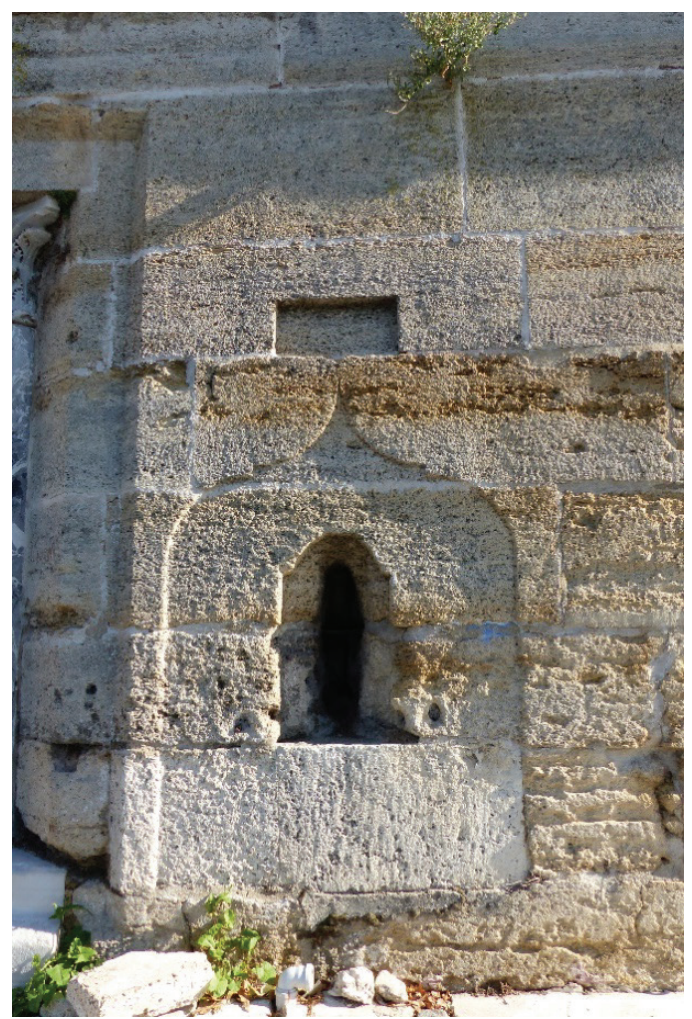

G. 3. Selimiye Külliyesi Duvar Çeşmesi, (N. Ç. Akçıl Harmankaya, 2018)

Kuzeydeki giriş cephesini de oluşturan dış avlu duvarı üzerinde yer alan bu çeşme tek yüzlü bir cephe çeşmesi olup yaklaşık 140x120 cm. ölçülerindedir. Duvar yüzeyinde yüzeysel bir niş şeklindeki bu çeşme dilimli bir kaş kemere sahiptir. Onarım ya da inşa kitabesi bulunmayan çeşmenin kemeri üzerinde $40 \mathrm{~cm}$. genişlikte kitabe konulmak üzere planlanmış olması muhtemel bir alan (kitabe yeri) mevcuttur. Ayna taşı da bulunmayan çeşmenin kaş kemerli yüzeysel nişinin kademeli ve dalgalı kemere sahip bir su akıtma çörteni vardır. Zaman içinde oldukça tahrip edildiği anlaşılan bu alanda tunç bir lüle veya musluk olmalıdır. Teknesinin su akıtma çörteni önünde dairevi kâse şeklinde olduğu tahmin edilmektedir. Günümüzde çimento malzeme ile doldurulan bu bölüm tas yuvası şeklinde olup tekne taşının ise sonradan değiştirildiği anlaşılmaktadır. Bu bölümün her iki yanındaki duvarda halka boşlukları vardır. $\mathrm{Bu}$ boşluklara bağlı bir zincir ve uçlarında su içmeye yarayan birer tas olması muhtemeldir. Bazı örneklerde çeşme musluğunu sabitleyen kenetler şeklinde kullanıldı̆̆ da görülmektedir. Ayrıca zeminde, kaldırım taşları arasında, çeşmenin su gideri ile ilişkisi olduğu düşünülen bir plastik boru dikkati çekmektedir (G. 4). 


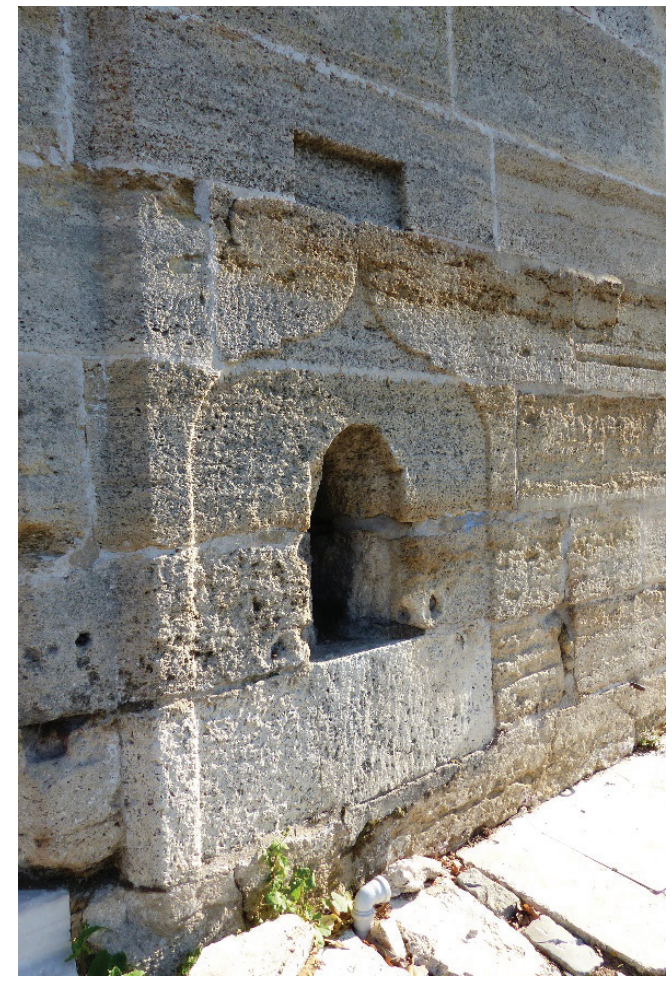

G. 4. Selimiye Külliyesi Duvar Çeşmesi Zeminde Görülen Plastik Tahliye Borusu,

(N. Ç. Akçıl Harmankaya, 2018)

Haznesiz sade bir duvar çeşmesi olan yapının arkasında kadınlar tuvaleti yer almaktadır (G.5). Çeşme ve tuvaletler ortak bir küfeki kırma çatı ile örtülüdür. Su ihtiyacını tuvalet ile aynı su hattından ya da yakınındaki eski Saray hamamından temin edildiği tahmin edilmektedir. Çeşmenin hemen yanında dış avlu duvarları devşirme bir sütun ile Mimar Sinan Caddesi'nden Taş Odaları sokağına doğru köşe yapmaktadır. Farklı bir uygulama olarak dikkati çeken bu köşe uygulamasında, çeşmede bu tasarıma özellikli bir katkı sağlamaktadır (G. 6). 


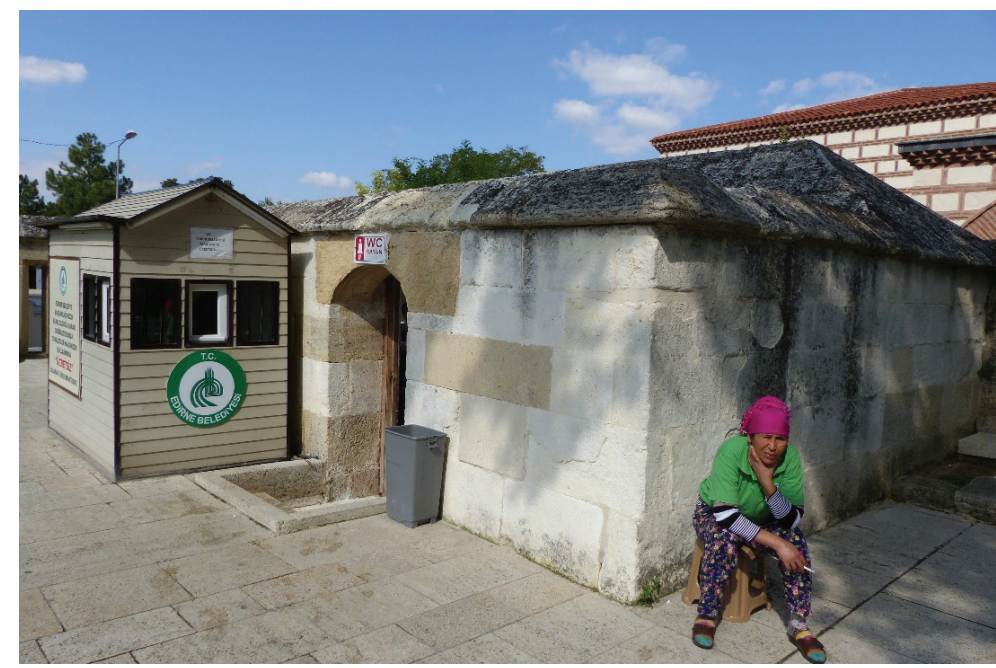

G. 5. Selimiye Külliyesi Çeşmesi Arkasındaki Kadınlar Tuvaleti, (N. Ç. Akçıl Harmankaya, 2018)

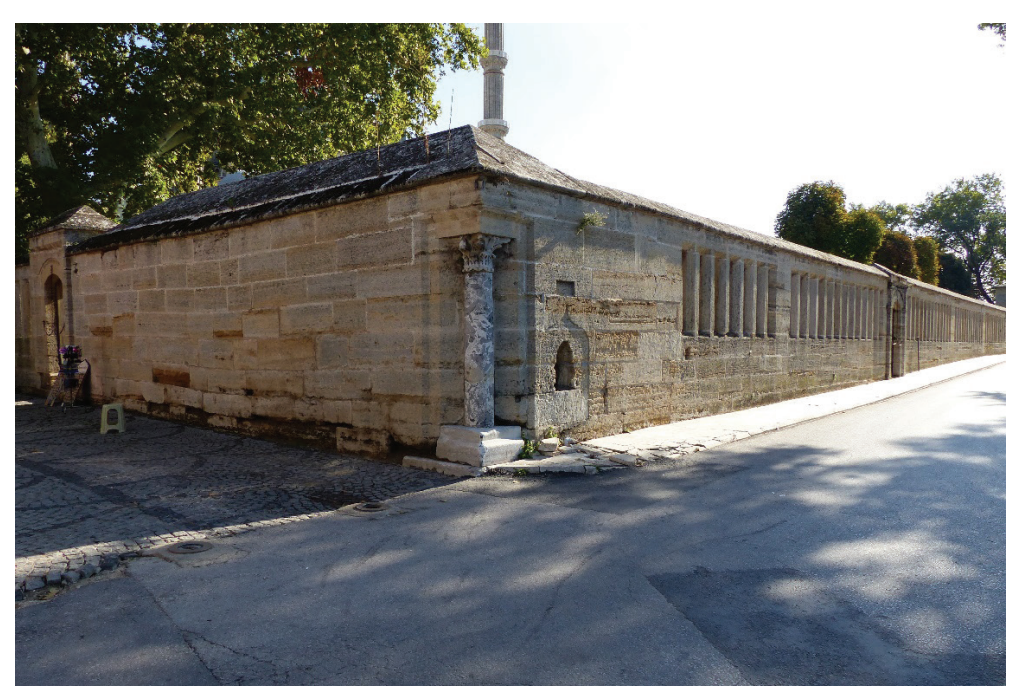

G. 6. Mimar Sinan Caddesi Üzerindeki Selimiye Külliyesi Duvar Çeşmesi ile Taş Odaları Sokak Köşesindeki Devşirme Köşe Sütunu, (N. Ç. Akçıl Harmankaya, 2018)

İnşa tarihi bilinmeyen bu çeşmenin mimarının da Sinan olduğuna ilişkin net bir belge bulunmamaktadır. Ancak Selimiye Camisinin inşasına ilişkin belgelerden ${ }^{10} \mathrm{Mi}$ mar Sinan’ın cami inşaatı boyunca vaktinin büyük çoğunluğunu Edirne'de geçirdiği

10 Mimar Sinan ile Divan-ı Hümayun arasında Külliyenin inşasına ilişkin otuz yedi yazışma bulunmaktadır. Bkz. R. Tuncay, a.g.e., s.3-12; N. Sönmez-Z. Sönmez, "Tarihi Belgelerin Işığında Edirne Selimiye Camisi”, a.g.e., s. 73-79. 
ve özellikle 1571-1573 yılları arasında üç yıl boyunca inşaatın başından ayrılmadığ ${ }^{11}$ ve 1584 yılında yıldırım düşmesinden zarar gören camiyi onardığ 1 anlaşılmaktadır ${ }^{12}$. 16 Mart 1576 tarihli bir ferman ise Selimiye'nin dış avlusunun, kapıları olmayan ahşap bir perdeyle çevrili olarak, bitirilmeden kaldığını ortaya koyar. Fermanda, Edirne kadısına, cemaatin zahmetlerine deva olmak üzere, "münasip mahalline bir kapı açıllp " inşa edilmesini emreder ${ }^{13}$. Bu nedenle avlu duvarları Sinan tarafindan cami ibadete açıldıktan sonra tamamlanmış olup söz konusu çeşme de avlu duvarlarının bir parçası olarak tasarımda yerini almış olmalıdır.

Selimiye Camii'nin su ihtiyacına ilişkin 9 Şubat 1572 tarihli Edirne Bostancıbaşı'sına yazılmış bir emir de caminin ve çeşmenin su ihtiyacının karşılanması bakımından oldukça önemlidir. Bu belgeden Edirne'nin Kayalar köyünden camiye su getirilmesi istenmektedir ${ }^{14}$. 23 Ekim 1574 tarihinde yine Edirne Bostancıbaşı'sına yazılan bir fermanda ise caminin eski suyoluna ilave edilmiş olan su için padişah hazinesinden 60000 akçe tahsis edilmiş olduğu, bu paradan 20000 akçe kaldığı, bütün suyunda bir lüle ve bir masura kadar olduğ $u^{15}$ öğrenilmektedir.

1982 yılında Selimiye Camii'nin ışıklandırılması için dış avluda yapılan kazıda cami ile hamam arasında bir sarnıç bulunduğu bilinmektedir ${ }^{16}$. Yapılan incelemelerde kemerli bir kanal ile buradaki suyun hamama ve eski saraya doğru akıtıldığı anlaşılmaktadır ${ }^{17}$. Bu sarnıç Caminin yerine yapıldığı Eski Saray'ın Baltacılar Koğuşu'nun bulunduğu yere rastlaması muhtemeldir. Edirne'nin ilk su ihtiyacının 15. yüzyılda Tunca nehri üzerine konulan dolaplarla karşılanmakta iken, şehre suyun sistemli bir şekilde gelmesi ancak 16. yüzyıl da Kanuni Sultan Süleyman döneminde Haseki Hürrem Sultan tarafindan Mimar Sinan'a yaptırılan su yolları ile sağlandığı bilinmektedir. ${ }^{18}$. Söz konusu çeşmenin de su ihtiyacını karşılayan bu hattın Edirne'nin kuzey-doğusundaki bu eski Taşlımüsellim suyollarının sonradan Selimiye Camiine kadar uzatılmış bir hattının devamı ile karşılandığı düşünülebilir ${ }^{19}$.

Yapılan araştırmada söz konusu çeşme, S. Ünver tarafından yitik taş $1^{20}$ olarak ta-

11 N. Sönmez, Z. Sönmez, a.g.e., s. 75 .

12 N. Sönmez, Z. Sönmez, a.g.e., s. 78.

13 Gülru Necipoğlu, Sinan Çağı ve Osmanlı İmparatorluğu'nda Mimari Kültür, Çev. Gül Çağalı Güven, İstanbul 2013, s. 326.

14 R. Tuncay, a.g.e., s. 6-7.

15 R. Tuncay, a.g.e., s. 12.

16 Yusuf Karabıyı,, Selimiye Camii Özel Defteri Edirne Eserleri ve Evliyaları, Edirne 1966, s. 37.

17 Oral Onur, Edirne Su Kültürü, İstanbul 1978, s. 61-62.

18 N. M. Köylüoğlu, a.g.e., s. 2.

19 Ünal Öziş, Yalçın Arısoy, Mimar Sinan'ın Suyolları, İzmir 1987, s. 2.

20 Yitik sahipleri eșyaları kaybolduğunda bu gibi Yitik taşlarına bakarlar, buluntu kendilerine ait ise alır, aksi takdirde dokunmazlardı. Yitik taşları eşyaların konulabileceği şekilde oyuk olmalıdır. Bu yerler, diğer taşların olduğu gibi, çoğunlukla cami, tekke, türbe yanlarında veya işlek cadde üzerlerinde olmalıdır. Hakkı Acun, "Birer Mimari Unsur Olarak Yardım Amaçlı Taşlar (Binek Taşı, Dinlenme Taşı, Sadaka Taşı, Köşe Pahlaması)", Konya Kitabı X, Yeni İpek Yolu Özel Sayısı, Konya 2007, s. 46 
nımlanmaktadır ${ }^{21}$. Sadaka taşları ${ }^{22}$ gibi yardım amaçlı olan bu taşlar kaybolan eşyanın sahibi tarafından bulunması için yapılan basit duvar nişleri şeklinde olup bilinen tek örneği, Sivas Kale Camii son cemaat yerinin kuzeybatı köşesindeki minare kaidesi üzerinde yer almaktadır ${ }^{23}$ (G. 7).

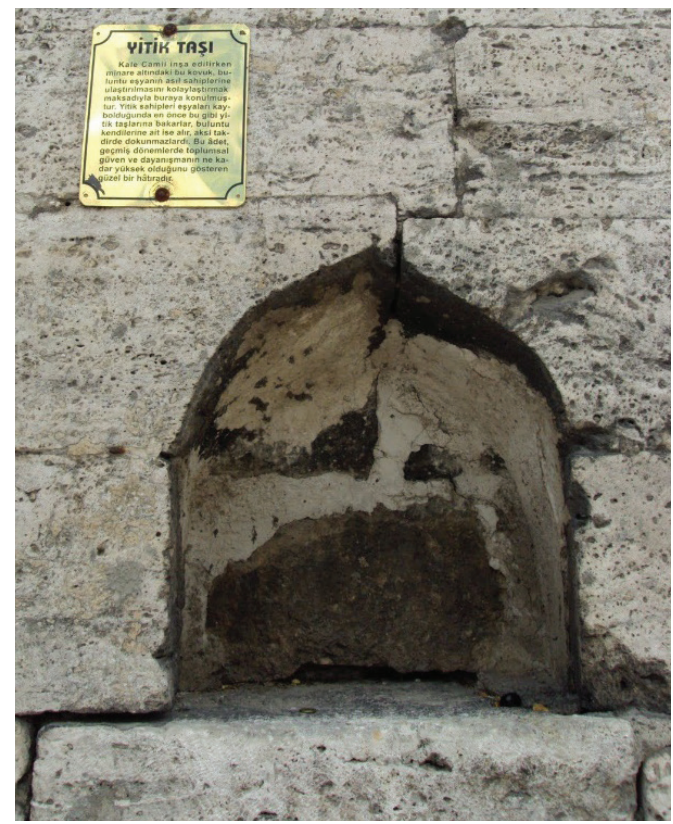

G. 7. Sivas Divriği Kale Camii Minare Kaidesindeki Yitik Taş1

(https://tr.pinterest.com/pin/540291286539262788/?lp=true, 18.02.2019)

Söz konusu yapının kemerli bir çeşme cephesi gibi özenli düzenlenmiş olması, üzerinde bir kitabe boşluğunun bulunması ve özellikle de eşya bırakılacak yeterlikte bir girintiye sahip olmaması gibi nedenlerden dolayı buranın yitik taşı olarak tanımlanamayacağını göstermektedir. Yitik taşlarının sadaka taşları gibi bir işlevi olduğu düşünüldüğünde Selimiye Camiinin kıble yönündeki arka kapısının özel olarak “ $D i$ -

21 “(...) Selimiye Camii Kayıp Eşyalar Bürosu olarak nitelenir. Payitahtta bir Osmanlı vatandaşı bir eşyasını kaybedecek ve o eşyayı bulan kişi onu alıp Selimiye Camii’nin ana giriş kapısının sol tarafında eski hamamın olduğu köşedeki duvarda bulunan yitik taşına bırakacak ve eşyasını kaybeden kişi kendinden emin bir şekilde oraya gelip eşyasını oradan alacaktı (...) Vakitlice üzerinde küçük bir kitabe varmış (...)” Bkz. Süheyl Ünver, "Sadaka Taşları", İnfak ve Zarafet Sadaka Taşlarının Mimari ve Kültürel Hususiyetleri, Haz. Şemsettin Şeker, Mustafa Yılmaz, İstanbul 2017, s. 216-217.

22 Cami, çeşme gibi yapıların önünde yer alan ve üzerlerine fakirler için para bırakılan taşlardır. Farklı çap, ebad, şekil ve türde olmakla beraber genellikle beyaz renkli, silindirik, çoğu antik mermer sütunlardır. Yere dikine gömülmüşlerdir H. Acun, a.g.e., s. 43; Hasan Özönder, "Türk Mahallelerinde Sadaka Taşlarının Yeri ve Önemi”, Uluslararası Dördüncü Türk Kültürü Kongresi Bildirileri 4-7 Kasım 1997, C. II, Ankara 2000, s. 156.

23 Yitik Taşı, yerden 1-1,25 m. yükseklikte sivri kemerli bir niş şeklindedir. Kaybolmuş bulunan eşyanın sahibine ulaştırılmasını kolaylaştırabilmek için buraya konulmuştur. H. Acun, a.g.e., s. 46. 
lenciler Kapısı" olarak adlandırıldı̆̆ı, caminin avlusunda ve diğer kapılarının önünde dilenci bulunmasının ise yasaklandığı bilinmektedir ${ }^{24}$. Dilenciler sadece bu kapının önlerine durur, yardım vermek isteyen cemaatte de bu kapıdan çıkarak sadaka verirdi. Ayrıca, belirli yerlerde özellikle de cami bahçesinde içleri oyulmuş sadaka taşları bulunurdu. Sadaka vermek isteyen yardımseverler bu taşların üzerine para koyar ihtiyacı olan da ihtiyacı kadar para alırdı. Bu gelenek Balkan Savaşları'na kadar devam etmiş sonrasında sadaka taşları ile birlikte ortadan kalkmıștır ${ }^{25}$.

\section{Değerlendirme}

Su yapıları içerisinde önemli bir yere sahip olan çeşmelerin en erken ve sade örnekleri kesme taştan sivri kemerli duvar nişleri şeklinde olup, kabartmalarla işlenmiş, taş veya mermer bir ayna taşı ve bunun ortasındaki lüle ile önündeki su teknesinden meydana gelmektedir. Klasik Osmanlı Döneminde de bu sade kuruluş devam eder. Edirne Selimiye Külliyesinin bir parçası olan bu çeşme de, dilimli kaş kemerli nişi ile oldukça sade bir düzenlemeye sahiptir. Bir cephe çeşmesi şeklindeki tasarımı ile Anadolu Selçuklu cami ve medreselerin cephesine yapılan çeşme ve sebilleri hatırlatmaktadır ${ }^{26}$. Özellikle dış avlu duvarı üzerindeki konumu ile İstanbul Hacı Evhad Camii (1585) çevre duvarlarının kuzey ve güney cephelerindeki cümle kapılarının yanında yer alan duvar çeşmeleri ile benzerlik göstermektedir ${ }^{27}$. Arkasında kadınlar tuvaleti bulunması ile su hattının ortak kullanılması pratik bir işlev kazandırmaktadır. Sinan'ın benzer uygulaması İstanbul Süleymaniye Camii (1550-1557) kuzeybatı dış avlu duvarları üzerindeki çeșmesinde de görülür. Buradaki çeșmenin de arkasında tuvaletler yer almaktadır.

Osmanlı döneminde Mimar Sinan'ın pek çok suyolu ve su yapısı inşa ettiği bilinmekle birlikte bunlar arasında çeşmelere ilişkin çok az bilgi edinilmektedir. Örneğin 1566 y1lı sonrası yazılan vakfiyesinde ${ }^{28}$ çeşmelere ilișkin; İstanbul'da çeșmeler, Has-

24 "(...) Cami avlusuna girmek için dokuz kapı bulunmakta olup bunlardan bir tanesi de "Dilenciler Kapısıdır" Caminin arkasında ve darülkurra ile darültedris arasında ve mihrap istikametindedir. O taraf cemaati camiye bu kapıdan girerler. Cenaze bu kapıdan çıkarılır. Caminin avlusunda ve diğer kapıların önünde dilenci bulunmak halkı iz'haç etmek katiyen yasak olduğundan namaz vakitlerinden evvel ve sonra cenaze vukuunda ramazan ve sair mübarek günlerde dilenciler bu iki bahçe arasındaki yolun iki tarafında kapıya kadar dizilirler. Sadaka vermek isteyenler dilencileri ancak burada bulabilirler (...) ”, Arif Dağdeviren, Edirne'de Sinan ve Selimiyesi, 1968, s. 8.

25 Y. Karabiyık, a.g.e., s. 15,42.

26 Avlu duvarları üzerinde yer almasa da özellikle Sivas Gökmedrese Çeşmesi (1271) ve Konya Sahip Ata Külliyesi (1258) portali, iki yanındaki sebil-çeșmeleri gibi giriș cephesi üzerindeki su yapılarıla benzerlik gösterdiği söylenebilir. Bu örnekler ile olan benzerlik yapıların giriș cephesinde, kapı yanında ya da yanlarında yer alan birer duvar çeşmeleri olmalarıyla ilgilidir. Bu örneklerin sayısını arttırmak mümkündür. Sivas Gök Medrese çeşmesi ve Konya Sahip Ata Külliyesi portal sebil-çeşmeleri için bkz. Y. Önge, Türk Mimarisinde Selçuklu..., s. 11-19.

27 M. Baha Tanman, "Hacı Evhad Külliyesi”, Dünden Bugüne İstanbul Ansiklopedisi, C.3, İstanbul 1994, s. 473-475.

28 Sinan'ın vakfiyeleri için bkz. İbrahim Hakkı Konyalı, Mimar Koca Sinan, İstanbul 1948, s. 13-28, 50-58. 
lar kazası Soğanlı köyünde çeşme, Vize sancağında Urgaz köyünde çeşme sayılmaktadır $^{29}$. Ayrıca Sinan'ın memleketi olan Kayseri-Ağırnas köyünde üç çeşmesi vardır. Biri Rum mahallesinde Karagöz Çeşmesi, İkincisi Kayseri-Bünyan yolu üzerinde Ağa Pınarı çeşmesi, üçüncüsü ise Sine Pınarı adlı çeşmesidir ${ }^{30}$. Eser sayıları birinden diğerine değişiklik gösteren tezkireleri arasında Tezkiretü'l Bünyan'da;

“(...) Bu zavallının, dünya padişahları, vezirler ve âyân adına resmini çizip inşa ettiği seksen cami ve dörtyüzden fazla mescid oldu; altmıs yerde medrese, otuz iki saray, on dokuz türbe, yedi darülkurra, on yedi imaret, üç darüş̧ifa, yedi yerde köprü, on beş suyolu kemeri, altı mahzen, on dokuz han ve otuz üç hamam bina olundu..." denilerek ${ }^{31}$ çeşmelere yer verilmemiş. Ancak, Tezkiretü'l Ebniye'de “(...) İstanbul'da su sıkıntısı çekildi, Kırkçeşme başhavuzunun suyu azaldı. Yine o taraflarda sular bulundu, Suyolları yapılması buyruldu. Gökkuşağı gibi yüksek kemerler yaptık, Suları ta şehre kadar çıkardık. Akıtıldı o dupduru su şehirde, Yapıldı üç yüzden fazla çeşme (...) '’32, denilerek en azından İstanbul'da isimleri ve yerleri belirtilmeyen üç yüzden fazla çeşme inşa ettiği öğrenilmektedir.

Mimar Sinan'ın bağımsız çeşme yapısı inşa etmek yerine genellikle cami avlu duvarları üzerinde konumlandırdığı çeşmeleri külliye inşa programına dâhil ettiği anlaşılmaktadır. Özellikle, İstanbul Süleymaniye Camii (1550-1557), Silivrikapı Hadım İbrahim Paşa Camii (1551), Kadırga Sokollu Mehmet Paşa Camii (1567-1572), Üsküdar Atik Valide Camii (1571-1584), Yedikule Hac1 Evhad Camii (1585), Fatih Mesih Mehmed Paşa Camii (1584-1586)'lerinde olduğu gibi Selimiye öncesi ve sonras1 Sinan yapılarında duvar çeşmeleri uygulaması ile sıkça karşılaşılmaktadı³ ${ }^{33}$ (G.8).

29 Afet İnan, Mimar Koca Sinan, Ankara 1968, s. 52.

30 İ. H. Konyalı, a.g.e., s. 105.

31 S. M. Çelebi, a.g.e., s. 45.

32 S.M. Çelebi, a.g.e., s. 103.

33 Yapılar hakkında detaylı bilgi için bkz. D. Kuban, Osmanlı Mimarisi, İstanbul 2007; Ayşe Denknalbant Çobanoğlu, "Silivrikapı Hadım İbrahim Paşa Camii’nin Plan Özellikleri ve Klasik Dönem Osmanlı Mimarlığı İçinde Benzer Örnekler Üzerine Bir Değerlendirme”, Art Sanat, S.11, İstanbul 2019, s. 101-137; G. Necipoğlu, a.g.e., 


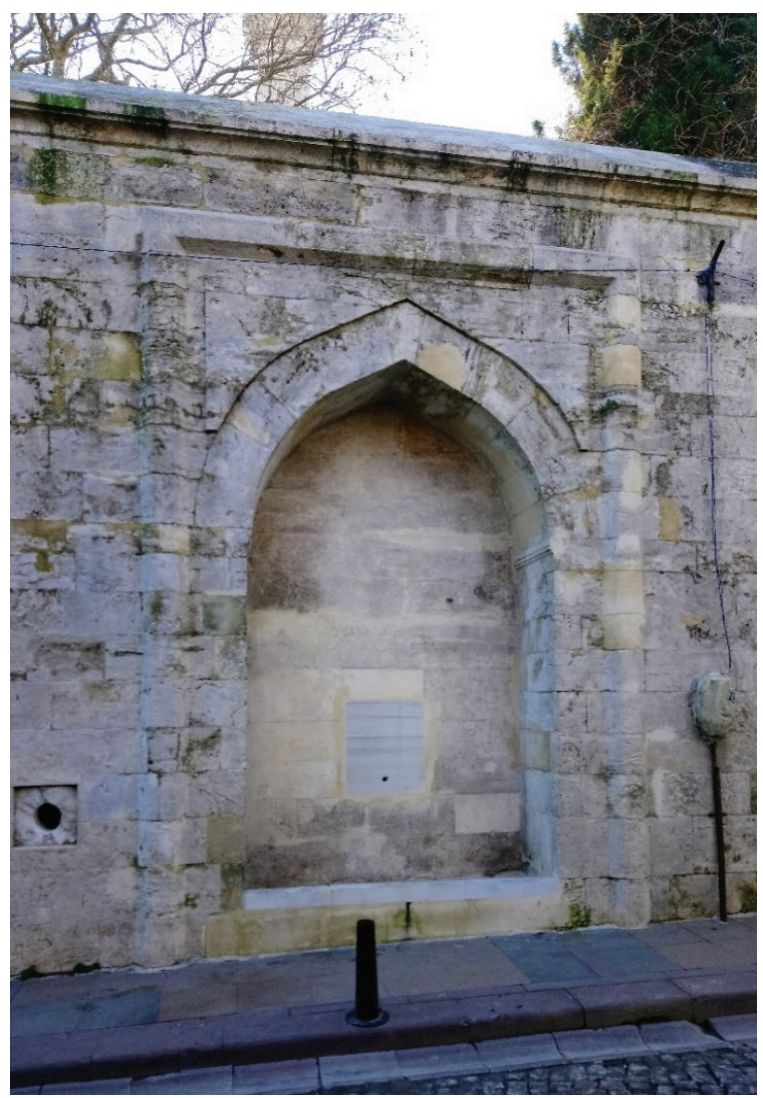

G. 8. İstanbul Süleymaniye Külliyesi, Kuzey Batı Avlu Duvarları Üzerindeki Çeşmesi

(N. Ç. Akçıl Harmankaya, 2019)

Duvar yüzeyinde oldukça sı̆̆ bir nişşseklinde kurgulanan çeşmenin benzerleri yine Sinan tarafından Selimiye Cami içinde, kapının her iki yanındaki, sebil-çeşmelerde de uygulanmıştır. Y. Önge tarafından tekne sebil ${ }^{34}$ olarak adlandırılan bu su yapılarında olduğu gibi söz konusu çeşmenin de teknesinin üst tarafının, yani nişin tabanın dairevi planlı bir tezgâh şeklinde olduğu düşünülmektedir. Tezgâha dökülebilecek suların akıtılması için, tezgâh tablasına küçük bir delik açılmış olmalıdır. Birer uçları niş duvarlarına zincirle bağlanmış, saplı birer maşrapa ile de tekneden ya da lüleden dökülen sudan içilebiliyordu. Günümüzde tezgâh tablasının olduğu yer çimento malzeme ile doldurulmuş olup teknesinin taşı ise tamamen değiştirilmiştir. Teknenin zemine yakın yerinde ise yine çimento ile doldurulmuş bir su tahliye deliğinin olduğu tahmin edilmektedir. Bu bölümün önünde zeminden çıkan bir plastik boru görülmektedir (G.9).

34 Yılmaz Önge, "Mimar Sinan'ın Sebilleri”, Uluslararası Mimar Sinan Sempozyumu Bildirileri (Ankara, 24-27 Ekim 1988), Ankara 1996, s.114. 


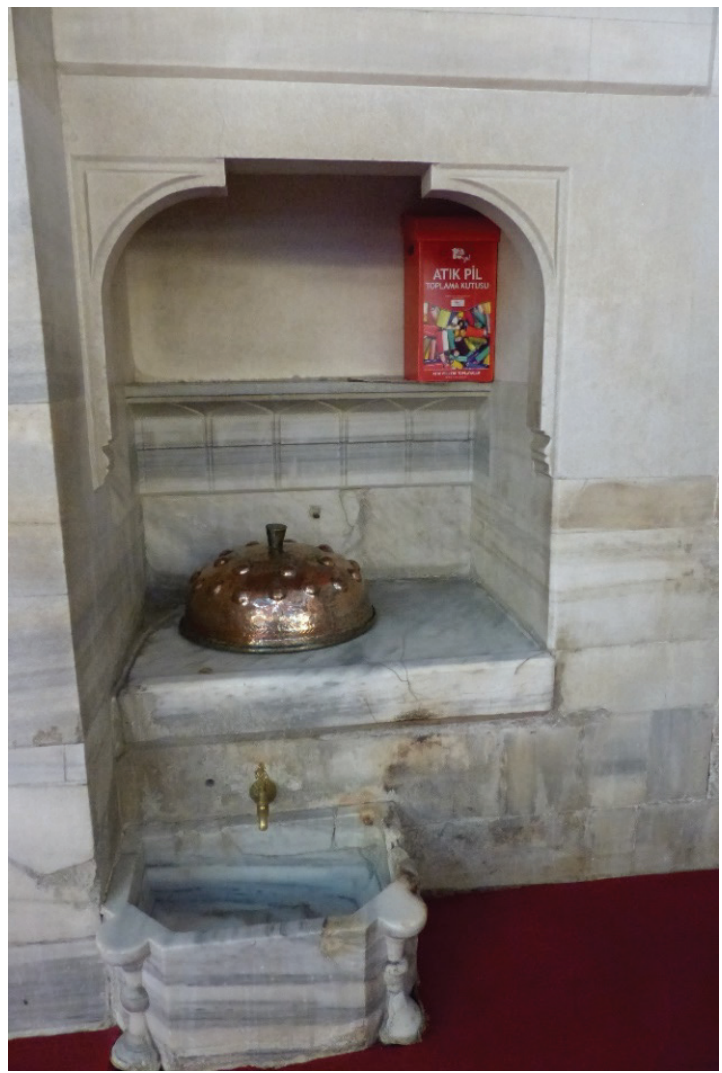

G. 9. Selimiye Camii İç Mekân Giriş Kapısı Sol Yanındaki Tekne-Sebil,

(N. Ç. Akçıl Harmankaya 2018)

Ayrıca Sultanahmet Camii’nin dış avlu duvarları üzerindeki orta kapısının avlu yönündeki ayaklarında da bu tip çeşmeler yer almaktadır. Kaş kemerli açıklıklara sahip bu çeşmeler birer niş şeklinde olup içinde birer musluk yeri bulunmaktadır. Giderleri zeminden $8 \mathrm{~cm}$. kadar yukarda, suluk tabir edilen bir uygulamaya sahip bu çeşmelerden daldırma ile su temin edilmektedir ${ }^{35}$. Selimiye çeşmesinin de benzer bir mimariye sahip olması, Sinan'ın öğrencisi ve halefi olan Mimar Sedefkâr Mehmed Ağa ile Sinan arasındaki usta çırak ilişkisinin Sultanahmet Külliyesi’nde ki mimari bir ifadesi olarak dikkati çekmektedir (G. 10). 


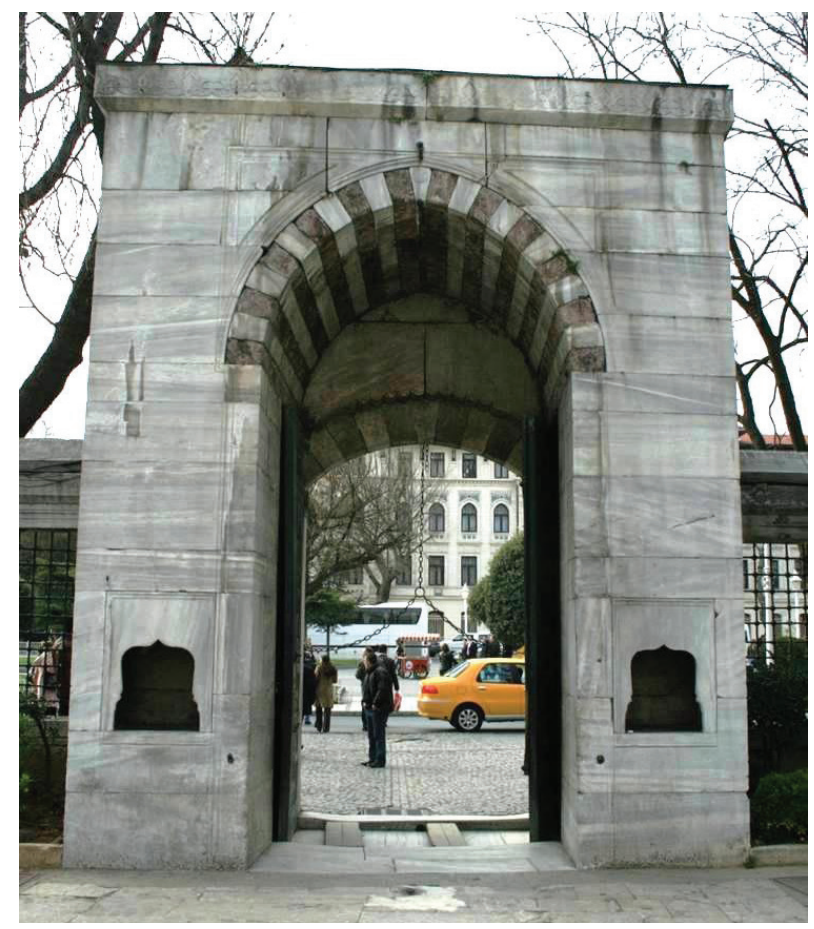

G. 10 Sultanahmet Camii Atmeydanı'na Bakan Avlu Kapısı İçindeki Çeşmelerden Biri (Ahmet Vefa Çobanoğlu, 2015)

Genellikle ç̧eşmelerin ayna taşı ya da kemerinin üzerinde, yapıların künyesi niteliğinde, banisinin adı, inşa tarihi ve Kuran'dan alınmış su ile ilgili ayet ve de hadislerin işlendiği taş ya da mermer bir levha şeklindeki kitabeler bulunmaktadır. Ancak çalışma konumuz olan bu çeşmede kitabe yeri boştur. Özgün inşa ya da tamir kitabesinin varlığı bilinmemektedir. Kitabe yerinin ölçüleri dikkate alındığında, birçok çeşme kitabesinde ve Emirgan Meydan Çeşmesinin ${ }^{36}$ (1782-1783) dört yüzünde yer alan celi sülüs hatlı kitabe kartuşlarında da okunduğu gibi "Mâşâ Allâh", ya da "(...)Hayatı olan her şeyi sudan (yarattı)", Kur'an: El-Enbiya Suresi 11/30. Ayetinin yazılı olması muhtemeldir.

\section{Sonuç}

Edirne Selimiye Külliyesi'nin bilinmeyen ve daha önce incelenmeyen bu duvar çeşmesi ile şadırvanı, abdest muslukları, iç mekânda giriş kapısının her iki yanındaki sebil-çeşmeleri ve müezzin mahfili altındaki sekizgen havuz dışında bir su yapısı daha olduğu tespit edilmektedir. Mimar Sinan'ın tezkire ve vakfiyelerinde, diğer bir-

36 Hüsamettin Aksu, Ahmet Vefa Çobanoğlu, “Emirgan Meydan Çeşmesi”, Sanat Tarihi Araştırmaları Dergisi, S.11, İstanbul 1992, s. 19-22. 
çok çeşmesi gibi adı geçmeyen bu çeşmenin kuzey dış avlu duvarları üzerinde bir sebil-çeşme şeklinde düzenlendiği tahmin edilmektedir. Çeşme, Mimar Sinan tarafından yapının dış avlu duvarları ve yanındaki devşirme köşe sütunu ile birlikte cami inşaatı bitirildikten sonra tamamlanmıştır. Eski Saray yolu olarak bilinen ana caddeye bakan konumu ile halkın su ihtiyacını karşılayan bu çeşme banisinin ve mimarının Edirne şehrine bıraktıkları önemli bir hayır eseri olmuştur.

Edirne Selimiye Külliyesi duvar çeşmesinde görüldüğü gibi Sinan'ın bağımsız çeşme yapısı inşa etmek yerine genellikle avlu duvarları üzerinde konumlandırarak çeşmeleri külliye inşa programına dâhil ettiği dikkati çekmektedir. Edirne çeşmeleri arasında özel bir yeri olduğu anlaşılan Osmanlı'nın Klasik döneminin bu gösterişsiz sade çeşme tasarımı ile Selimiye Camii’nin mimari dehasına anlamlı bir katkı sağlamaktadir.

Finansal Destek: Yazar bu çalışma için finansal destek almamıştır.

\section{Kaynakça/References}

ACUN, Hakkı, "Birer Mimari Unsur Olarak Yardım Amaçlı Taşlar (Binek Taşı, Dinlenme Taşı, Sadaka Taşı, Köşe Pahlaması)”, Konya Kitabı X, Yeni İpek Yolu Özel Sayısı, Konya 2007, s. 43-61.

AKÇIL HARMANKAYA, N. Çiçek, Mimar Sinan Camilerinde Sembolizm, İstanbul 2018.

AKSU, Hüsamettin; ÇOBANOĞLU, Ahmet Vefa, "Emirgan Meydan Çeşmesi", Sanat Tarihi Araştırmaları Dergisi, S.11, İstanbul, Aralık 1992, s. 19-22.

CANAN, İbrahim, “Osmanlı'da Su Kültürü ve Kaynakları”, Osmanlı Su Medeniyeti Uluslararası Sempozyum Bildiriler (5-8 Mayıs 2000), İstanbul 2000, s. 231-244.

ÇELEBİ, Sâî Mustafa, Yapılar Kitabı (Tezkiretü'l-Bünyan ve Tezkiretü'l-Ebniye) Mimar Sinan'ın Anıları, Çev. Hayati Develi, Samih Rifat, İstanbul 2002.

ÇELEBİ, Evliya, Günümüz Türkçesiyle Evliya Çelebi Seyahatnamesi, Haz. Seyit Ali Kahraman, Yücel Dağl1, 3. Kitap, İstanbul 2016.

ÇOBANOĞLU, Ahmet Vefa, "Sultanahmet Külliyesinde Sebiller ve Çeşmeler”, 17. Yüzyıl Osmanlı Kültür ve Sanatı, 19-20 Mart 1998 Sempozyum Bildirileri, İstanbul 1998, s. 57-76.

DAĞDEVİREN, Arif, Edirne'de Sinan ve Selimiyesi, 1968.

DENKNALBANT ÇOBANOĞLU, Ayşe, “Silivrikapı Hadım İbrahim Paşa Camii’nin Plan Özellikleri ve Klasik Dönem Osmanlı Mimarlığı İçinde Benzer Örnekler Üzerine Bir Değerlendirme", Art Sanat, S.11, İstanbul Ocak 2019, s. 101-137.

EGLI, Ernst, Osmanlı Altın Çağının Mimarı Sinan, Çev. ve Der. İbrahim Ataç, İstanbul 2009.

EYİCE, Semavi, "Çeşme”, Türkiye Diyanet Vakfı İslam Ansiklopedisi, C. 8, İstanbul 1993, s. 277-287.

INAN, Afet, Mimar Koca Sinan, Ankara 1968.

KARABIYIK, Yusuf, Selimiye Camii Özel Defteri Edirne Eserleri ve Evliyaları, Edirne 1966.

KARADEMIR, Murat, Edirne Çeşmeleri, Edirne 2008. 
KONYALI, İbrahim Hakk1, Mimar Koca Sinan, İstanbul 1948.

KÖYLÜOĞLU, Neriman Meriç, Edirne’de Osmanlı'dan Günümüze Su Yapıları, Edirne 2001.

KUBAN, Doğan, Sinan'ın Sanatı ve Selimiye, İstanbul 1997.

KUBAN, Doğan,, Osmanlı Mimarisi, İstanbul 2007.

KURAN, Aptullah, Mimar Sinan, İstanbul 1986.

MÜLAYİM, Selçuk; ÇOBANOĞLU, Ahmet Vefa, "Selimiye Camii ve Külliyesi”, Türkiye Diyanet Vakfı İslam ansiklopedisi, C.36, İstanbul 2009, s. 430-434.

NECIPOĞLU, Gülru, Sinan Çağı ve Osmanlı İmparatorluğu'nda Mimari Kültür, Çev. Gül Çağalı Güven, İstanbul 2013.

ONUR, Oral, Edirne Su Kültürü, İstanbul 1978.

ÖNGE, Yılmaz, “Mimar Sinan'1n Sebilleri”, Uluslararası Mimar Sinan Sempozyumu Bildirileri (Ankara, 24-27 Ekim 1988), Ankara 1996, s. 114.

ÖNGE, Yılmaz, “Anadolu Beylikler Döneminin Çeşme, Sebil ve Şadırvanları”, Uluslararası Osmanlı Öncesi Türk Kültürü Kongresi Bildirileri (4-7 Eylül 1989 Ankara), Ankara 1997, s. 199-214.

ÖNGE, Yılmaz, "XI. Yüzyıldan XIX. Yüzyıla Kadar Anadolu Su Mimarisinde Çeşme, Sebil ve Şadırvanlar”, Türk Mimarisinde Selçuklu ve Osmanlı Dönemlerinde Su Yapıları, Ankara 1997, s. 11-19.

ÖZIŞ, Ünal; ARISOY, Yalçın, Mimar Sinan'ın Suyolları, İzmir 1987.

ÖZÖNDER, Hasan, “Türk Mahallelerinde Sadaka Taşlarının Yeri ve Önemi”, Uluslararası Dördüncü Türk Kültürü Kongresi Bildirileri 4-7 Kasım 1997, C. II, Ankara 2000, s. 155-422.

SÖNMEZ, Zeki, Mimar Sinan İle İlgili Tarihi Yazmalar-Belgeler, İstanbul 1988.

SÖNMEZ, Neslihan; SÖNMEZ, Zeki, “Tarihi Belgelerin Işığında Edirne Selimiye Camii”, Uluslararası Mimar Sinan Sempozyumu Bildirileri (Ankara, 24-27 Ekim 1988), Ankara 1996, s. 73-79.

TANMAN, M. Baha; "Hacı Evhad Külliyesi”, Dünden Bugüne İstanbul Ansiklopedisi, C. 3, İstanbul 1994, s. 473-475.

TUNCAY, Rauf, "Edirne'de Selimiye Camii”, Belgelerle Türk Tarihi Dergisi, S. 23, Ankara 1969, s. 3-12.

ÜNVER, Süheyl, "Sadaka Taşları”, İnfak ve Zarafet Sadaka Taşlarının Mimari ve Kültürel Hususiyetleri, (Haz. Şemsettin Şeker-Mustafa Y1lmaz), İstanbul 2017, s. 216-217.

https://tr.pinterest.com/pin/540291286539262788/?lp=true/ Erişim Tarihi: 18.02.2019. 